\title{
ENSINO DE LÍNGUA PORTUGUESA E INQUIETAÇÕES TEÓRICO-METODOLÓGICAS : OS GÊNEROS DISCURSIVOS NA AULA DE PORTUGUÊS E A AULA (DE PORTUGUÊS) COMO GÊNERO DISCURSIVO
}

\author{
Mary Elizabeth CERUTTI-RIZZATTI*
}

- RESUMO: Este artigo tem como tema a aula de Português, focalizando a abordagem dos gêneros discursivos nas práticas de ensino e aprendizagem em língua materna. Trata-se de um estudo de natureza qualitativa, de cunho etnográfico, parte de um projeto maior que implica a constituição de um banco de dados sobre a aula de Língua Portuguesa na Educação Básica em redes públicas de ensino. Como parte desse projeto, este estudo objetiva responder à seguinte questão: que implicações metodológicas são depreensíveis no processo de ensino e aprendizagem de língua materna, na Educação Básica, organizado a partir da concepção dos gêneros discursivos como instrumentos para o desenvolvimento de práticas de leitura e escrita? Para tanto, topicaliza o trabalho com os gêneros do discurso na aula de Português, tanto quanto focaliza a aula (de Português) como gênero discursivo. As bases teóricas são estudos sobre o tema derivados de Mikhail Bakhtin e teorizações sobre letramento derivadas de Brian Street. As conclusões, a partir da abordagem de tipo etnográfico, sugerem dificuldades dos professores participantes deste recorte de pesquisa para elaborações didáticas a partir dos gêneros discursivos em sua ação metodológica, tanto quanto dificuldades em constituir a aula (de Português) como gênero discursivo.

- PALAVRAS-CHAVE: Aula de Português. Gêneros discursivos. Práticas de letramento.

\section{Introdução}

Uma das inquietações que nos têm ocupado nas ações de pesquisa que vimos empreendendo são as relações entre os saberes produzidos nas universidades no que respeito à Linguística Aplicada e à forma como esses saberes efetivamente têm contribuído na discussão de problemas linguísticos socialmente relevantes (MOITA LOPES, 2006), tal qual nós, linguistas aplicados, tomamos hoje como nosso objeto de estudo. No nosso caso, especificamente, esse objeto de estudo tem intrínsecas relações com o universo escolar. Assim, os problemas linguísticos socialmente relevantes, em nossos recortes de pesquisa, vinculam-se ao processo de ensino e aprendizagem de práticas de leitura e escrita na Educação Básica.

* UFSC - Universidade Federal de Santa Catarina. Núcleo de Estudos em Linguística Aplicada. Santa Catarina Florianópolis - SC - Brasil. 88040-970 - mary.elizabeth@ufsc.br. 
As teorizações acadêmicas sobre gêneros do discurso e letramento revelam-se construtos potencialmente relevantes para a ressignificação das práticas didáticopedagógicas no campo do ensino e da aprendizagem da leitura e da escrita na escola. Sob a perspectiva dos gêneros, parece-nos muito significativa a busca de uma ação escolar comprometida com a forma com que os seres humanos usam a linguagem em suas práticas interacionais cotidianas, a vontade de conferir ao processo pedagógico um encaminhamento que revele menor artificialidade e favoreça a aprendizagem significativa. Já sob a perspectiva dos estudos de letramento, parece haver a sensibilidade em relação à forma como as diferentes culturas usam a língua escrita, tanto quanto a busca pela hibridização entre letramentos dominantes e letramentos vernaculares, o que se revela uma possível ancoragem para uma ação escolar mais sensível aos usos da escrita na sociedade.

Nesse universo, porém, uma questão instigadora nos ocupa atualmente possivelmente se trate de uma inquietação historicamente posta e que ganha evidência, a cada tempo histórico, sob roupagens diversas: como professores da Educação Básica têm se valido dessas discussões teóricas para potencializar as práticas de uso da língua escrita no universo pedagógico em que se inserem? A busca por construir inteligibilidades nesse universo tem como fundamento a preocupação em empreender uma atividade acadêmica em Linguística Aplicada que efetivamente repercuta de algum modo para a coconstrução de novos caminhos na resolução de problemas linguísticos socialmente relevantes; nesse caso, a dificuldade escolar para potencializar a mobilidade dos alunos em sua esfera social, tanto quanto mediar seu acesso a esferas sociais distintas da sua, fazendo-o por meio da linguagem escrita. Este estudo se ocupa de discussões atinentes a essa inquietação.

\section{Ensino e aprendizagem de língua materna: duas décadas en passant}

Desde a publicação dos Parâmetros curriculares de Língua Portuguesa (BRASIL, 1997) e da eclosão, ainda que tardia no Ocidente, do pensamento de teóricos como Mikhail Bakhtin e L.S. Vigotski e de seus seguidores no Brasil, a concepção de língua como objeto social - ancorada em filosofias da existência e em epistemologias de base sócio-histórica - ganhou espaços expressivos em nível nacional, redundando na preocupação em empreender o ensino de língua materna ancorado em usos sociais da linguagem.

No que respeita à língua escrita - foco historicamente privilegiado no ensino de português na escola e objeto de nosso interesse neste artigo -, os estudos de letramento, fundamentados sobremodo em abordagens de natureza etnográfica empreendidas ou disseminadas por pensadores como Brian Street, David Barton e Mary Hamilton (2000), ganhou igualmente lugar na propagação de novos 
pressupostos para o ensino de língua materna no país. Obras como Portos de passagem, de João Wanderley Geraldi (1991), e Os significados do letramento, organizada por Ângela Kleiman (1995) - ambas da década de 1990 -, podem ser tomadas hoje, em nosso entendimento, como alimentadoras da mudança de foco do ensino de Português no país.

Ensinar língua materna com base nos usos sociais da linguagem passou a ser um ideário, em grande medida, sustentado nestas duas vertentes teóricas: a concepção de gêneros de discurso, de herança bakhtiniana (BAKHTIN, 2003), e a concepção de letramento ideológico, originada em Street (1984). Seguramente muitos ganhos e muitos desafios advieram com o desenvolvimento dessa nova etapa na construção de conhecimentos sobre o ensino da linguagem no Brasil.

Os ganhos têm sido, em nosso entendimento, vinculados a uma mobilização dos profissionais da área em fazer grassar processos de ensino que tenham como viés metodológico a compreensão de que os gêneros discursivos são - tal qual Maingueneau (2008, p.152, grifo nosso) entende ser tradição da AD francesa conceber - "dispositivos de comunicação sócio-historicamente condicionados que estão em constante mudança", o que nos parece honrar pressupostos bakhtinianos - tanto quanto vigotskianos - de que as interações humanas são viabilizadas por meio dos usos da linguagem e que tais usos têm configurações relativamente estáveis que atendem a propósitos sociais e que precisam ser entendidas à luz de sua historicidade. Ganhos, ainda a nosso ver, correspondem ao entendimento relativamente consensual hoje de que os usos da língua escrita não podem ser tomados como sinônimos de erudição - o que possivelmente privilegiaria gêneros do discurso secundários, se pensássemos em Bakhtin (2003) - e que precisam ser entendidos à luz da lógica que os justifica no âmbito microcultural em que fazem sentido (ERICKSON, 1989; STREET, 1984).

Há, no entanto, em nossa compreensão, estrangulamentos nesse movimento de consolidação, ampliação e legitimação de um novo olhar para o processo de ensino da língua materna à luz dessas vertentes, o que entendemos ser prototípico de toda movimentação teórica que ganha vulgarização científica em manuais, cursos de formação continuada, apostilas e afins. Concebemos que a expansão de uma vertente teórica tem como correlatos espraiamento conceitual e implicações hermenêuticas inerentes ao fato de que as apropriações conceituais se dão por filtros axiológicos e de filiação epistemológica que caracterizam os estudiosos, o que se justificaria, por si só, a condição de homens e mulheres histórica, cultural e geograficamente situados que os caracteriza.

Trata-se, em última instância, de um custo inerentemente compatível com o próprio eixo dessas vertentes teóricas: a língua é usada por homens reais, em tempos histórico e sociais definidos. Tais homens necessariamente têm suas construções axiológicas, as quais os fazem refratar, em uma atitude responsiva 
(BAKHTIN, 2003), as teorias com que têm contato, conferindo a sua filiação contornos desses filtros social, histórica e culturalmente construídos. Assim, o espraiamento teórico - com suas virtudes e vícios - explicar-se-ia à luz do próprio eixo sobre o qual se estruturam tais teorias: a inserção/materialidade histórica dos estudiosos da linguagem. Não há como haver abstrações teóricas assépticas, o que as inquietações tematizadas na seção que segue possivelmente ilustrem com precisão.

\section{Gêneros do discurso: ambientações/inquietações em esferas de ensino}

Uma das inquietações com que temos convivido nos últimos anos e que decorre da interação com educadores em atuação em escolas da rede pública de ensino é a forma como esse ideário das duas últimas décadas parece voltarse contra sua própria lógica em muitos ambientes microculturais. A educação em linguagem, com base na concepção de gêneros discursivos (BAKHTIN, 2003) e letramento ideológico (STREET, 1984), em alguns entornos, tem assumido configurações que, a nosso ver, requerem estudo zeloso, em razão do foco em conhecimentos de referência e/ou da dimensão categorial e taxionômica de que se têm revestido.

Possivelmente a manifestação mais efetiva desse processo seja a preocupação em arrolar gêneros discursivos determinados para seriações escolares específicas, à guisa de orientar o professor em seu processo de ensino da língua materna por meio dos usos sociais da linguagem. Temos, aqui, em nossa compreensão, um processo categorial embrionário que artificializa os usos da língua como se eles fossem passíveis de catalogação e determinação a priori para seriações específicas, em uma acepção universalizante.

Sob essa perspectiva, entendemos que os gêneros viram objeto de ensino ${ }^{1}$ em e por si mesmos, deixando de ser instrumentos para que a escola promova o desenvolvimento de habilidades de leitura e escrita dos alunos em prática sociais de usos da linguagem as quais sejam relevantes na necessária hibridização entre as experiências locais com escrita e as experiências globais (STREET, 2003a, 2007) de que os alunos, situados sócio-historicamente, precisam se apropriar para trânsito em esferas sociais distintas das suas.

Vemos esse movimento - que entendemos embrionária e perigosamente categorial, em documentos oficiais, como referenciais curriculares e olimpíadas

Ainda que os PCNs de Língua Portuguesa (BRASIL, 1998) refiram-se aos gêneros como objetos de ensino, entendemos essa referência na condição de instrumentos para o desenvolvimento das práticas de linguagem. 
de Língua Portuguesa, e em produções acadêmicas de natureza diversa. ${ }^{2}$ Ao que parece, em nome de favorecer a ação do professor de educação básica, temos nos ocupado com arrolar gêneros cuja abordagem mostrar-se-ia mais adequada para esta ou aquela faixa de escolarização, recomendando que os professores de Língua Portuguesa permaneçam na abordagem de um mesmo gênero pelo tempo necessário para consolidar a apropriação das práticas de linguagem a ele correlatas. Sob essa perspectiva, se o trabalho com o gênero for apressado, os alunos não se apropriariam das práticas de linguagem constituídas por meio desse mesmo gênero, no entanto o que nos parece acontecer de fato é a preocupação com a apropriação do gênero, sob vários aspectos, concebido como artefato.

Diante da depreensão de concepções como essas, via inserções de natureza etnográfica em escolas públicas, ${ }^{3}$ temos nos perguntado se posturas dessa natureza não subvertem, em boa medida, a gênese do movimento que desencadeou a mudança na abordagem de Língua Portuguesa na escola há cerca de duas décadas. Queríamos, sobremodo a partir de meados da década de 1990, que a vida que pulsa na linguagem extramuros da escola entrasse nessa mesma escola, de modo a contribuir para que o ensino de língua materna fosse significativo, sobretudo para as classes sociais que têm, na escola, como propõe Kleiman (1995), sua principal agência de letramento.

Em que reside tal subversão de gênese? Ao categorizarmos os gêneros por adequação a faixas etárias distintas, recomendando que o professor se debruce sobre um gênero ou outro de modo a promover a apropriação de tais gêneros estudados, não estaríamos propondo uma categorização a priori da vida extramuros antes de inseri-la na ambientação escolar e, o mais sério, fazendo-o a priori a despeito da natureza situada das práticas de letramento (HAMILTON, 2000)? Dizendo de outro modo: não estaríamos "empacotando a vida da linguagem" e lhe conferindo contornos e previsibilidades cuja precisão é questionável? Nesses casos, não estaríamos substituindo um tipo de estudo categorial - textos organizados em tipologias e tomados como artefatos abstraídos dos processos interacionais - por outro, que se proclama eminentemente interacional?

Se não nos equivocamos nesse desenho, isso parece ser contraface do que Bakhtin (2004) e Vigotski $(2000,2001)$ quiseram significar ao tratar de usos da língua à luz das filosofias da existência. Os homens usam a língua assim ou assado, diversamente, dialeticamente. Contra-argumentos podem apontar espontaneísmo e relativismo em nossa reflexão, a que antecipamos defesa, advogando em favor da compreensão de que a língua viva, a língua em uso, tem

\footnotetext{
Entendemos eticamente imprópria a nomeação desses exemplos, o que pode ser facilmente verificado com pesquisas on-line bastante simplificadas.

3 Tais inserções correspondem ao corpo de pesquisas que vêm sendo empreendidas pelo grupo de pesquisa NELA - Núcleo de estudos em Linguística Aplicada - do qual sou parte.
} 
a variabilidade como propriedade - vejamos a concepção de enunciados-tipo e enunciados-ocorrência (MAINGUENEAU, 2001) - e os "tipos relativamente estáveis de enunciados" (BAKHTIN, 2003) por meio dos quais ganha visibilidade são reais e humanos exatamente em razão de serem relativamente estáveis, o que, a nosso ver, não autoriza empacotamentos exaustivos e taxionômicos acompanhados de propostas de esquadrinhamento de um rol de itens previamente estabelecidos como relevantes na abordagem em turmas de alunos social e historicamente situadas.

Então, como trabalhar os gêneros do discurso na escola? Eis a questão que se nos afigura relevante: o foco não nos parecer ser trabalhar os gêneros, mas trabalhar a língua em uso, tendo os gêneros como (mega)instrumentos, tal qual propõem Schnenuly e Dolz (2004), em que pese, em nossa compreensão, serem esses autores bases teóricas em que se ancoram muitos dos empacotamentos a que temos assistido. Se os gêneros são (mega)instrumentos, tal qual propõem os estudiosos de Genebra, ou se são dispositivos de comunicação sóciohistoricamente situados, tal qual propõe Maingueneau (2008), não podem ser o foco do processo de ensino e aprendizagem da língua materna, mas meio para que ela se dê.

Essas inquietações vêm de inserção em campo e têm nos permitido montar paulatinamente um banco de dados significativo sobre episódios que temos testemunhado no dia a dia de nossas relações com diferentes escolas, em diferentes espaços socioculturais. Tentamos visibilizar esse olhar de insiders nas seções que seguem.

\section{Ação docente de transposição X apropriação/construção docente da ação}

A vinheta narrativa a seguir remete à forma como a elaboração didática (HALTÉ, 2008) constitui atividade complexa, dado que o que se observa, em boa medida, é a transposição didática (PETIT JEAN, 2008); nesse caso, não do conhecimento tal qual produzido na universidade, mas desse mesmo conhecimento recondicionado e veiculado em documentos oficiais: o professor não transpõe da academia, transpõe dos documentos. O fato é que não reelabora, tão somente aplica, o que, em nossa compreensão, decorre da não apropriação desse saber, condição necessária para reelaborá-lo à luz das práticas de letramento situadas (HAMILTON, 2000). Não o fazendo, limita-se a transpor uma construção apriorística, uniformizante e, por isso mesmo, não raro sem sentido para ele mesmo e para os alunos. 
A professora da primeira série do ensino médio [escola da rede pública] precisa trabalhar com crônicas porque a escola está participando das Olimpíadas de Língua Portuguesa. Ela não domina o gênero, não tem conhecimentos de referência sobre crônicas e confessa não ter tempo para estudar e ler de modo a apropriar-se dos saberes implicados hoje em sua ação didática. E nem "concorda muito" com a escolha das Olimpíadas: admite em sala nunca ter trabalhado crônica com uma turma de primeiro ano, só no terceiro. Então, lê em voz alta, nos manuais do Gestar II e no livro das Olimpíadas encaminhado pelo MEC, o que é crônica, enquanto os alunos desatentos parecem não ouvir. O foco do material institucional são os autores de crônicas e a natureza dos temas; a esfera de circulação, as interações que o gênero medeia/constitui e o modo como os recursos linguísticos são mobilizados para que tais interações aconteçam parecem estar em flagrante segundo plano no tratamento do material em questão. Eis, em nossa avaliação, o olhar no gênero como artefato. Dois meses de trabalho depois - em aulas de cerca de vinte minutos, encurtadas em razão de mazelas institucionais historicamente instauradas na escola e [as aulas] flagrantemente prejudicadas por evidente descaso da turma - um dos alunos, em entrevista diz: "Não aprendi nada nas aulas de Português neste ano; não sei ainda o que é crônica!" (IRIGOITE, 2011, p.143).

Trata-se, nesse caso, de uma professora comprometida - talvez muito mais do que isso, angustiada, aflita - com os resultados de sua ação docente. Ela procura se informar sobre as novas tendências do ensino de Língua Portuguesa, mas a forma como essas informações chegam até ela - por meio de cursos de formação continuada e via documentos institucionais como Olimpíadas da Língua Portuguesa (BRASIL, 2010), na rotina apressada de seu cotidiano, não lhe permite apropriar-se dos conhecimentos de base, nem tampouco do conhecimento de referência sobre os gêneros trabalhados, quer porque não disponha do tempo necessário para tal, quer pela natureza lacunar dessas fontes de informação.

Assim, sua ação parece se limitar a uma ação-tarefeira, repassadora de atividades pensadas por profissionais que dominam tais teorias e que constroem propostas de ação bem intencionadas, mas cuja operacionalização peca pela superficialidade em razão de não haver apropriação conceitual efetiva por quem as desencadeia. Assim, não nos parece haver possibilidade de empreendimento de elaborações didáticas, tal qual propõem Halté (2008); a transposição didática (PETIT JEAN, 2008) é o corolário evidente. 


\section{Os gêneros discursivos na formação do professor de Português na Universidade}

Qual seria a solução para problemas dessa natureza, problemas dos quais a vinheta imediatamente anterior não é senão uma - dentre muitas - ilustração materializada? Entendemos que a resposta possivelmente seja a formação do professor de Língua Portuguesa nos cursos de Letras e nos programas de pós-graduação, isso porque os professores já titulados realizam processos de formação continuada com profissionais das universidades, egressos de cursos de pós-graduação em Linguística (Aplicada) e/ou pesquisadores da área. Assim, em nosso entendimento, os projetos pedagógicos e as grades curriculares tanto de cursos de licenciatura em Letras quanto de cursos de pós-graduação em áreas de concentração na Linguística Aplicada têm de ser sensíveis ao quadro que se desenha em escolas reais, na vida real. Não se trata de uma formação teleológica, tanto quanto não se trata de uma formação teoreticista, como escreveu Bakhtin (2003), criticando a separação abstrata entre o mundo da cognição e o mundo da vida e defendendo a necessidade de resgatar a unidade perdida.

Eis, aqui, o célebre embate entre pesquisadores e teóricos que advogam em favor de oferecer bons materiais didáticos aos professores por conta de esses mesmos professores não disporem de tempo e/ou de preparo para a elaboração didática, ${ }^{4}$ em contraponto a estudiosos que defendem que tais professores precisam dispor desse tempo e contar com essa preparação. ${ }^{5}$ Inscrevemo-nos no segundo grupo, porque compreendemos que, se tais professores não estiverem preparados teoricamente, não saberão como lidar com bons materiais de ensino - ainda que se trate de manuais, quase receituários -, limitando-se, como no caso da professora cuja ação foi topicalizada na vinheta anterior, à ação tarefeira de aplicar um material zelosamente produzido, mas que não significa para ela, nem tampouco para os alunos.

Com relação à formação docente e ao zelo pela sensibilidade em relação à "escola real", por parte dos programas pedagógicos dos cursos de licenciatura em Letras e dos cursos de pós-graduação em Linguística Aplicada, vejamos a vinheta narrativa a seguir:

Licenciandas em Letras, em exposição informal das atividades realizadas ao longo do período de estágio, registram ter trabalhado com enredos de filmes porque teriam sido orientadas a não focalizar "gêneros batidos",

4 A exemplo de Magda Soares, autora de livros didáticos.

5 A exemplo de João Wanderley Geraldi, em cujas falas revela preocupação com a preparação do professor em detrimento da oferta de materiais prontos, posição manifestada em palestra em Florianópolis, no ano de 2008. 
a exemplo de crônicas e artigos de opinião. Ficamos sabendo de seu esforço e dedicação no estudo dos conhecimentos de referência sobre o gênero enredo de filmes, de modo a objetivar um trabalho produtivo e enriquecedor, e elas narram, entre outras atividades, terem ocupado algumas aulas com a discussão sobre bitolas de filmes, parte de um conjunto de conhecimentos que não detinham e do qual tiveram de se apropriar antes de dar a aula. Quando questionamos sobre como abordaram a compreensão leitora dos enredos trabalhados, elas excelentes alunas no curso - sorriem e percebem que isso não foi feito. Os alunos tomaram conhecimento, dentre outras particularidades teóricas do estudo do cinema, de bitolas de filmes e de outros itens da formação de referência de cineastas e/ou roteiristas. Em contrapartida, não endereçaram sua atenção para as relações entre configuração dos roteiros e elenco de produção dos filmes - afinal, as interações a que os roteiros se prestam parecem ser entre roteiristas e equipe de produção/ elenco dos filmes, dado que o público espectador não deve ter contato com o roteiro de filme como gênero discursivo. Não atentaram, ainda, para questões de reflexão crítica como gastos de produção demandados pelos roteiros, premiações/projeção internacional dos roteiristas e configuração das nações no mercado cultural da filmografia - em um contexto de classes de adolescentes consumidores de produções americanas de escala industrial -, nem tampouco atentaram para as razões dos diálogos diretos, do uso de pronomes dêiticos na fala das personagens, da forma como as categorias nominais referenciavam o mundo ali ficcionalizado dentre outras tantas questões implicadas na mobilização dos recursos linguísticos nesse gênero específico, o que possivelmente teria contribuído para potencializar a formação dos leitores de outros tantos gêneros infinitamente mais comuns nas diversas interações que ocupam a vida cotidiana desses alunos. (CERUTTIRIZZATTI, 2010, p.4, grifo do autor).

Esse exemplo, também uma materialização pontual que dá conta de todo um conjunto de cenas de que nosso banco de dados vem se compondo, parece indicar a prevalência do instrumento sobre sua própria função: o foco termina sendo o gênero em si mesmo, o que se evidencia na exploração dos conhecimentos de referência sobre o gênero - nesse caso, enredo de filme - e na preocupação da orientação do formador de que o período de estágio contemplasse gêneros "não batidos".

A nós, parece exótico ocupar dois meses de trabalho com enredos de filmes quando as interações humanas estão a demandar excelência nos usos da linguagem em configurações bem mais prosaicas, sobretudo quando se trata de um universo de adolescentes que lidam mal com usos da língua escrita em interações comuns em seu cotidiano - a exemplo de compreensão leitora de notícias de jornais ou da produção de uma justificativa em cadastro para vaga de trabalho; isso sem mencionar a educação para a leitura de um conto ou de uma crônica por pura fruição. 
O que levaria docentes formadores a posturas como essa senão tomar o instrumento - gênero - em lugar de sua própria função - dispositivo de interação por meio do qual as práticas de linguagem seriam de algum modo objeto de estudo, digamos, "mais naturalizado" na escola?

\title{
O foco excessivo nos gêneros chamados midiáticos
}

Sem dúvida, o jornal, como suporte de uma série de gêneros discursivos, é um interessante recurso para discussão em classe, sobremodo se considerado seu trânsito on-line modernamente, o que favorece, em grande medida, o acesso a ele na escola. Os gêneros discursivos que têm o jornal como suporte, é fato, instauram relações importantes na vida humana, mas tais relações precisam ser entendidas à luz de sua natureza constitutiva. Mais uma vez, os excessos em nome de uma pseudomodernidade teórico-metodológica:

\begin{abstract}
A professora alfabetizadora olha para nós e conta o trabalho interessante que realizou com a turma com os gêneros anúncio classificado e manchete de jornal. Perguntamos a ela por que não vemos evidências, em sua ação ao longo do ano, de trabalhos com lenda, conto, fábula, história em quadrinhos, parlenda - gêneros cujas estruturas narrativas e eixo na ludicidade nos parecem tão recorrentes nas leituras para crianças pequenas nas famílias e na sociedade. Ela nos responde que os gêneros midiáticos são o foco da escola porque a tônica dos cursos de formação tem sido essa, e o texto literário é um texto de difícil abordagem. Insistimos, perguntando a ela se acha que crianças costumam ler anúncios classificados e manchetes de jornal cotidianamente, se os usos sociais da escrita nesse tempo da vida costumam ter esses propósitos interacionais, e ela confessa que não entende muito bem a razão de privilegiar os gêneros que têm o jornal como suporte - tem feito isso nos últimos dois anos; antigamente trabalhava com narrativas - mas a escola tem essa opção e ela acha que precisa seguir porque há muito não estuda. (CERUTTI-RIZZATTI, 2010, p.8).
\end{abstract}

Sabemos, de longa data, a importância das sequências narrativas na formação em linguagem nas séries iniciais. O brinquedo e a figurativização da realidade na infância foram discutidos por inúmeros teóricos, dentre os quais possivelmente baste referenciarmos Jean Piaget e L.S. Vigotski. Piaget (2007) mostrou, com sua teoria de estágios implicacionais de desenvolvimento infantil, o percurso da ação operatória para a ação operatória reversível, do raciocínio ancorado na concretude dos fatos para o raciocínio hipotético-dedutivo, na abstração formal. Já segundo Vigotski (2000), a criança lida com mundo na figurativização do real e, em se tratando da apropriação da língua escrita, o brinquedo é embrionariamente 
um processo de simbolismo do qual o simbolismo de segunda ordem constituído pela escrita decorre em grande medida, até que essa modalidade da língua seja internalizada como simbolismo de primeira ordem.

A figurativização do mundo, a ludicidade e o brinquedo têm implicações flagrantes com as sequências narrativas ficcionais presentes em gêneros discursivos como lenda, fábula, conto fantástico, conto de fadas e afins. Temos assistido a um movimento bastante significativo de diversidade de gêneros no processo de alfabetização, o que, sem dúvida, parece-nos enriquecedor quando não denega os gêneros com sequências narrativas ficcionais tão importantes nessa fase do desenvolvimento infantil. Mais uma vez, os excessos que temos testemunhado em nome do que entendemos ser uma compreensão arrevesada dos pressupostos bakhtinianos nos quais as discussões sobre gêneros discursivos na escola se ancoram em alguma medida.

\section{As listagens de gêneros por série em documentos institucionais de ensino}

Em nome de contribuir para a qualificação da ação docente, sistemas de ensino em nível municipal e estadual, manuais pedagógicos de formação continuada e livros didáticos ${ }^{6}$ tendem a arrolar listagens de gêneros por seriações escolares. Os propósitos parecem nobres e possivelmente tenham relações com fomentar a construção da excelência dos alunos em um maior número de gêneros possível ao longo do processo de educação básica.

As perguntas que nos temos feito são: O objetivo da educação em língua materna é essa tentativa - que todos sabemos, de antemão, inócua - de exauribilidade? E, não sendo exauribilidade, não seria essa uma tentativa de aquilatar conhecimentos sobre o maior número de gêneros possível, categorizando-os, empacotando-os e distribuindo-os? Onde estaria a vida da linguagem nesse tipo de postura? O foco, em ambos os casos, não é o gênero como objeto? O objetivo da educação em língua materna não seria potencializar ao máximo as habilidades de uso da linguagem em interações sociais significativas, as quais se consubstanciam por meio de gêneros discursivos que são ou não recorrentes e cuja diversificação é consequência da ampliação das interações e não necessariamente propulsora delas? Um trabalho em favor disso não tem de ter como eixo basilar quem são os sujeitos, onde estão, o que fazem e de que forma a escola pode ressignificar suas relações interacionais, processo em que os gêneros discursivos são instrumentos e não fins? Vejamos um exemplo que semeia angústias como essas.

6 Mais uma vez, em nome de eventual impropriedade ética, entendemos desnecessário nomear os itens mencionados, sobretudo dada a compreensão de que quaisquer pesquisa on-line menos pretensiosa pode mapear fontes desse tipo. 
Recebemos um e-mail de uma professora de Português da quinta série [escola da rede pública] participante de um dos cursos que ministramos há algum tempo. Ela está empenhada em ensinar aos alunos a produção de uma resenha e pede nossa ajuda para lidar com a incapacidade das crianças para emitir opiniões sobre o livro lido: um romance de mistério. Segundo ela, os alunos, embora sejam empenhados e bons leitores, apenas resumem o livro e não conseguem se posicionar, criticando ou elogiando a obra e sustentando sua apreciação com argumentos convincentes. Em resposta, perguntamos a ela se não seria mais produtivo discutir os resumos, resgatar a estrutura narrativa, empreender um processo de implementação da compreensão leitora em que os alunos pudessem refletir sobre o conteúdo do livro, sobre as interações que o romance de mistério institui, sobre os recursos linguísticos mobilizados para tecer a narrativa de mistério, sobre as demandas inferenciais requeridas no desvendamento do assassino. Mencionamos estudos de Piaget e a dificuldade de meninos dessa idade para refletirem sobre a violência implicada no romance, evocando argumentos ancorados na abstração dos fenômenos sociais, dado estarem em um "entrelugar" entre as operações concretas e as operações formais (SARDÁ, 2008). Como resposta, soubemos que a supervisora da rede entendeu nossos encaminhamentos como defesa do conceito de "prontidão" e evocou as teorizações sobre gêneros para defender a posição de que as crianças têm de trabalhar com todos os gêneros que circulam socialmente, independentemente da idade em que se encontram. Argumento adicional foi que, dentre os gêneros arrolados para essa série nos referenciais curriculares do Estado, estava a resenha e que deveria ser trabalhada. (CERUTTI-RIZZATTI, 2011, p. 15).

Acompanhamos por um tempo o desenvolvimento do trabalho dessa professora e compartilhamos de sua desolação diante de alunos que não conseguiam argumentar sobre a violência como fenômeno social mais amplo, estabelecendo relações com o crime cometido no romance de mistério, nem tampouco se mostraram aptos para veicular em suas resenhas conclusões acerca de estilo literário e de estratégias narrativas. Muitos dentre os meninos e as meninas, na maioria de dez anos de idade, segundo ela, terminaram por desgostar da leitura daquele romance de mistério em razão das demandas impostas em nome da produção da resenha.

As ambientações/inquietações até aqui arroladas as quais ilustramos com exemplos pontuais à guisa de conferir materialidade empírica à discussão nos limites que uma abordagem no gênero artigo científico viabiliza compõem o que entendemos ser um perigoso movimento no universo escolar: a posição descendente das costumeiras curvas a que as inflamações teóricas, de quando em quando, submetem a escola. 
Expliquemos isso melhor. O universo da alfabetização conviveu/convive com esse movimento, de forma, a nosso ver, dolorosa. Ferreiro e Teberosky (2007) eclodiram na década de 1980 em nome de um argumento incontestável: as crianças raciocinam sobre a escrita enquanto se apropriam dela; logo, não podem ser submetidas a um processo asséptico de sentidos por ocasião da alfabetização. Essa fantástica eclosão, como todo fenômeno do tipo, foi alimentada por fontes de segunda mão que levaram as ideias de Emília Ferreiro ao discurso e à ação de alfabetizadores que possivelmente nunca tenham tomado um livro da autora em mãos. Os equívocos conceituais e metodológicos típicos dos movimentos teóricos de grande repercussão nas escolas terminaram por incendiar, duas décadas depois, argumentos em favor do retorno aos métodos fônicos: ${ }^{7}$ as ideias de Ferreiro, em tese, seriam a causa-mor da desqualificação dos processos educacionais no nível da alfabetização; importaria, pois, reverter o quadro. O temor derivado desse movimento associa-se a possibilidade de perdermos um de nossos grandes ganhos: contextos de sentido para alfabetizar, perda que teria como origem uma proposta teórica que, sob vários aspectos, foi objeto de apropriação arrevesada.

Entendemos que as teorizações sobre gêneros discursivos, hoje, parecem estar no desenho descendente da curva cujo topo foi a segunda metade da década de 1990 e a primeira metade da década de dois mil. Caso não discutamos com mais vagar arrevesamentos teóricos que têm tido lugar em nome de concepções bakhtinianas, equívocos a que vimos assistindo em muitas escolas social e historicamente situadas nas quais empreendemos nossos ensaios etnográficos, é possível que as críticas comecem a se endereçar à teoria em si mesma e não a suas corruptelas, tal qual se deu no universo da alfabetização. Importa, pois, verticalizar estudos dessa ordem em nome de não perdermos o grande ganho de hoje: ensinar língua materna por meio de práticas sociais de uso da linguagem.

\section{A aula (de Português) como gênero discursivo: implicações das práticas de letramento para o engajamento nas interações didáticas}

Tendo materializado, em exemplos derivados de geração de dados por meio de ações de pesquisa de tipo etnográfico, em diferentes recortes empreendidos por nosso grupo de pesquisa, passamos a discutir um desdobramento que tem ganhado contornos expressivos em nossos estudos: a aula de Português como gênero discursivo.

Matêncio (2001, p.201) focaliza a aula de português como gênero e entende que "[...] a aula é um dos gêneros pelos quais se materializa o discurso didático."

Estudos com base nas neurociências (DEHAENE, 2007) têm sustentado, hoje, argumentações em favor do retorno dos processos fônicos. 
Segundo a autora, considerar as especificidades da aula de língua materna requer a articulação de zonas de produção discursiva engendradas na interação didática, o que ganha visibilidade em diagrama proposto por ela, tal qual segue:

Diagrama 1 - Interação didática

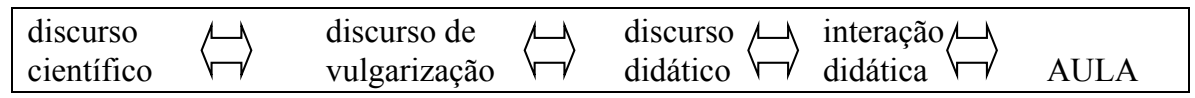

Fonte: Matêncio (2001, p.202).

Esse diagrama remete, em nossa compreensão, ao percurso a que já fizemos alusão nesta discussão, fundamentalmente: construção do conhecimento teórico-científico no campo da Linguística Aplicada, vulgarização desse conhecimento em textos institucionais, em manuais de ensino, em cursos de formação e afins, seguida pela elaboração ou transposição didática dependendo de como esse discurso se organiza e se efetiva e, enfim, a interação didática que constitui a aula.

Esta é a questão nevrálgica que gostaríamos de focalizar nesta seção: para que a aula se constitua como tal, importa que haja o engajamento dos participantes na interação didática que constitui o gênero aula; nesse caso, aula de Português. Segundo Matêncio (2001, p.203, grifo nosso), importa:

[...] não limitar o estudo da aula a sua dimensão textual (interativa), o que
seria o caso se fossem deixadas de lado as condições sócio-históricas
que interferem em sua produção, a saber: a delimitação de papéis sociais
e comunicativos aos interlocutores, a dimensão espaço-temporal do
evento, as relações complexas entre oralidade e escrita na coconstrução
dos objetos discursivos em sala de aula, a motivação e os objetivos
envolvidos na configuração da interação; enfim as restrições
institucionais também determinantes da materialidade do
texto.

Nossas experiências etnográficas nas escolas em que nossa inserção tem tido lugar vêm nos mostrando resistências discentes no que respeita ao engajamento nas interações didáticas. Dado o enfoque de nossos estudos ser a língua escrita, essa discussão remete ao conceito de eventos de letramento (HEATH, 2001; STREET, 1988; BARTON, 1994; HAMILTON, 2000), concebidos como os acontecimentos em que a escrita tem lugar na interação humana. Segundo Hamilton (2000), os eventos são a ponta do iceberg do qual as práticas de letramento são a base. As práticas, por sua vez, são concebidas como as vivências, a valoração, as construções culturais no bojo das quais os eventos têm lugar e delineiam seus contornos (STREET, 1988, 2003b, 2007). 
Para Hamilton (2000), os eventos de letramento implicam a consideração de participantes, artefatos, contextos e ambientes. Haver participantes implica haver engajamento interacional. Se, paralelamente a essa ancoragem teórica, retomarmos a concepção de gêneros discursivos como dispositivos de interação (MAINGUENEAU, 2001) e, tal qual Bakhtin (2003), entendermos que os usos da língua se dão em gêneros discursivos, comungamos com a concepção de que os gêneros implicam processos interacionais de usos da língua, tanto quanto os eventos de letramento implicam processos interacionais em que a escrita está presente. Logo, a aula de Língua Portuguesa, quando tem a leitura e a escrita como mote, tomando-as em usos sociais da língua o mais naturalizados possível em gêneros discursivos, implica a existência de um processo interacional. Assim, para haver a aula como gênero do discurso, há que haver interação didática (MATÊNCIO, 2001) e, para haver interação, tem de haver participantes engajados.

Nossas vivências etnográficas em escolas que compõem nosso universo de pesquisa vêm nos permitindo compartilhar de um processo que tem se tornado um verdadeiro drama para professores de Língua Portuguesa: a dificuldade de consolidar uma aula e a dificuldade de constituir eventos de letramento em que a língua escrita esteja sendo efetivamente usada em interações entre professor e alunos e entre alunos e alunos, isso porque grande parte dos alunos, em inúmeras classes, não têm se engajado efetivamente de modo a consolidar relações intersubjetivas, ou seja, não se estabelecem de fato as interações didáticas constitutivas do gênero aula (MATÊNCIO, 2001).

Temos tido testemunhos constantes de aulas que "não acontecem", porque não é possível ao professor empreender a construção de um tópico, desenvolvendo seus objetivos didático-discursivos, tal qual propõe Matêncio (2001). Segundo a autora, na aula, há focos temáticos convergentes, há focos divergentes e há focos predominantes. Ela menciona, ainda:

[...] focos discursivos metalinguísticos, visando à construção do saber nomear, [...] focos discursivos que incidem sobre os modos de realizar as tarefas, objetivando a construção do saber fazer, e focos conceituais, privilegiando a construção de saberes sobre o objeto de ensino e aprendizagem. (MATÊNCIO, 2001, p.51).

Para que os focos discursivos convirjam ou divirjam, no entanto, é necessário que haja interação entre professor e alunos e entre alunos e alunos. Quando essa interação não se dá, por conta de não haver o engajamento dos envolvidos, não se consolida a aula como gênero discursivo, porque não há interação efetiva. Ainda Matêncio (2001, p.151): 
Existem, é claro, as interações entre os pares que mantêm o tópico, vinculando-se ao objetivo didático da interação, mas [...] ou elas são inseridas na interação principal ou são ignoradas pelo professor. [...] Essas interações entre os pares são de interesse se consideradas como microinterações que intervêm no desenvolvimento da interação principal em sala de aula (podendo [...] desviar o tópico).

As inserções etnográficas em ambientações educacionais diferenciadas, nas escolas públicas em que vimos interagindo com alunos e professores, têm nos mostrado uma sobeja dificuldade dos professores e nossa, em nossas pesquisasação em auferir o engajamento dos alunos nas interações didáticas que, segundo Matêncio (2001) constituem a aula como gênero discursivo. Em que pesem ancoragem teórica consolidada, planejamento colegiado de ações, recurso a estratégias tecnológicas e comportamentos afins, temos provado, em muitas circunstâncias, o fracasso de não conseguirmos constituir interações sociais por meio da aula.

Dificuldades dessa natureza remetem-nos a uma reflexão sobre práticas de letramento (STREET, 1988, 2003, 2007; BARTON, 1994; HAMILTON, 2000). Nossas propostas de ensino de língua materna no que respeita à escrita - foco de nossa ação - nesses ambientes específicos não têm redundado em aulas de Língua Portuguesa - a interação didática não ocorre por conta do não engajamento de grande parte dos alunos; logo não há a aula como gênero discursivo.

Interações de outra ordem, via gênero entrevista face a face com os alunos, têm nos mostrado uma significativa indiferença em relação ao fato de a aula não acontecer, a exemplo das transcrições a seguir que são parte de uma de nossas pesquisa-ação (IRIGOITE, 2011, p.195)

Em grande parte das aulas de leitura observadas, percebemos um aparente desinteresse dos alunos: reclamavam do tamanho do texto a ser lido; faziam outras atividades não condizentes com a aula, como mexer no celular, fazer a unha e ouvir música no MP3, sem ao menos abrir o material da aula; sempre perguntavam antes de qualquer atividade se valia nota e se era para entregar. As aulas no laboratório de informática eram ainda piores: os alunos ficavam jogando ou assistindo vídeos na internet, sem ouvir absolutamente nada o que a professora diz. O nível de participação dos alunos era quase nulo: sempre os mesmos dois ou três se ofereciam para ler um texto e tentavam responder às perguntas da professora; a eles se juntavam mais alguns estudantes tidos como "tímidos", que prestavam atenção, mas não participam oralmente. Até perguntas mais simples, de cunho pessoal, como "o que vocês sabem ou já viram sobre tal assunto, tal gênero?", não recebia nenhuma resposta. (Diário de campo, nota n.5, novembro de 2009 a junho de 2010). 
Quando, por meio de entrevista face a face, os alunos foram interpelados sobre as razões de seu não engajamento às aulas, enunciaram posicionamentos como os que seguem.

(6)

Moro sozinho e trabalho num supermercado das 13 às 22 horas, todos os dias. Só venho para a escola porque minha mãe me obriga e para "marcar presença", pois não tenho ânimo para estudar de verdade, estou sempre muito cansado. - Entrevista com um aluno do primeiro ano que saiu da escola duas semanas depois. Maio de 2010.

Quando insistimos, na busca por construir inteligibilidades naqueles espaços destinados a potencializar suas práticas de uso da linguagem, procurando ouvir deles em que e o que as aulas de Língua Portuguesa deveriam melhorar para que houvesse seu engajamento como participantes das interações didáticas, registramos:

Não sei dizer o que se deve melhorar nas aulas de português. O problema é comigo. Não quero saber de assistir aula, de estudar, de ler... A gente não consegue aprender. Olha só, o semestre começou há quatro meses, não é? Até agora eu não aprendi nada! Não gosto de ler, só parte de esportes do jornal e propaganda com mulher. Em casa? Minha família também não gosta de ler. Tenho um monte de livro didático, mas minha mãe quer jogar fora. E pra que estudar? Nós não vamos passar de ano mesmo. E a senhora sabe que existe uma maneira de ganhar muito dinheiro sem estudar [... $]^{8}$ (IRIGOITE, 2011, p.238).

As teorizações anteriormente mencionadas sobre práticas de letramento têm se eliciado nessa busca de construir inteligibilidades sobre as razões pelas quais não há engajamento dos alunos de modo que as interações didáticas constituam-se em uma aula. O que temos concluído é que as práticas de leitura e de escrita, que se estabelecem por meio de gêneros discursivos caros à escola, a exemplo da crônica, parecem não significar para esses alunos, de modo que lidar com interações consubstanciadas por meio de gêneros como esse não converge com suas praticas de letramento. Talvez mais sério ainda: parece haver uma significativa dessimetria entre práticas de letramento da esfera escolar e práticas de letramento das famílias das quais esses alunos são originários.

Essa compreensão evidentemente não invalidaria o esforço da escola nem tampouco o nosso, nas inserções etnográficas que temos empreendido, dado

8 Menção subjacente à venda de drogas no morro em que mora. 
o entendimento de que cumpre à educação em língua materna - nesse caso, à educação no que respeita à modalidade escrita - ressignificar práticas de letramento vernaculares, de modo a promover hibridização dessas práticas com práticas de letramentos dominantes (STREET, 2003a, 2007; ROJO, 2009).

Para que isso se dê, no entanto, importa que as práticas de letramentos dominantes ganhem sentido no universo das práticas de letramento vernaculares, para que sejam refratadas e haja hibridização. Isso não parece acontecer nesses entornos, nos quais, como evidenciam nossas entrevistas, não há expectativas desses alunos de transitarem por outras esferas sociais, uma vez que seu universo microcultural (ERICKSON, 1989) parece retido em um círculo de práticas vernaculares que bastam por si sós. Como sinalizar para além desse círculo possivelmente seja o maior desafio da escola contemporânea no que respeita à consolidação da aula de língua materna que contempla interações sociais por meio da modalidade escrita. É certo que as discussões sobre a aula como gênero discursivo demandariam uma abordagem mais verticalizada no que respeita a implicações e particularidades da interação verbal, enfoque do qual abrimos mão em razão da necessária brevidade deste texto.

\section{Considerações finais}

As inquietações registradas neste artigo, ao mesmo tempo em que derivam de um banco de dados em construção e têm suscitado interessantes discussões no grupo de pesquisa em que têm lugar, trazem consigo, em nosso entendimento, componentes que extrapolam a dimensão acadêmica para ganhar a sociedade mais ampla: a alimentação de bolsões de baixo alfabetismo, tal qual apontam indicadores do Inaf/2009 (INSTITUTO PAULO MONTENEGRO, 2009). Enquanto nós, linguistas aplicados, vimos historicamente nos empenhando para significar, em se tratando de problemas linguísticos socialmente relevantes, parece que a forma como as teorizações que temos produzido chegam até os universos socioeconomicamente desprivilegiados não tem conseguido repercutir nesses mesmos ambientes, quer por conta de dificuldades para elaboração didática, o que tem implicações com o modo como estamos formando os licenciados nas universidades, quer porque as práticas de letramento da escola não se mostrem suficientemente sensíveis em relação às práticas de letramento locais, inviabilizando hibridizações tal qual propõe Street (2003a).

CERUTTI-RIZZATTI, M. E. Portuguese language teaching and theoretical-methodological concerns: discourse genres in Portuguese classes and (Portuguese) classes as a discourse genre. Alfa, v.56, n.1, p.249-269, 2012. 
- ABSTRACT: This paper focuses on Portuguese language classes, concentrating on the discourse genre approach applied to native language teaching and learning practices. This qualitative and ethnographic study is part of a larger project that also involves a database creation of Portuguese classes taught in public schools at Elementary Education level. The following research question is discussed: What are the methodological implications of the process of native language teaching and learning at Elementary School level, organized in terms of the concept of discourse genre as a tool for the development of reading and writing practices? Accordingly, this study stresses the work with discourse genres in Portuguese classes and takes (Portuguese) classes to be a discourse genre. The theoretical framework includes discourse studies by Mikhail Bakhtin and theories on literacy elaborated on Brian Street. The ethnographic approach findings suggest that teachers face difficulties to deal with didactic elaborations couched in discourse genres in their methodological actions, as well as conceiving of (Portuguese) classes as a discourse genre.

- KEYWORDS: Portuguese classes. Discourse genres. Literacy practices.

\section{REFERÊNCIAS}

BAKHTIN, M. Marxismo e filosofia da linguagem: problemas fundamentais do método sociológico na ciência da linguagem. Tradução de Michel Lahud e Yara F. Vieira. 11.ed. São Paulo: Hucitec, 2004.

Os gêneros do discurso. In: . Estética da criação verbal. Tradução de Paulo Bezerra. 4.ed. São Paulo: Martins Fontes, 2003. p.261-306.

BARTON, D. Literacy: an introduction to the ecology of written language. Cambridge: Blackwell, 1994.

BARTON, D.; HAMILTON, M.; IVANIC, R. Situated literacies. London: Routledge, 2000.

BRASIL. Olimpíadas de Língua Portuguesa. Brasília: MEC, 2010.

Parâmetros Curriculares da Educação Nacional: língua portuguesa. Secretaria de Educação Fundamental. Brasília, DF: MEC/SEF, 1998.

CERUTTI-RIZZATTI, M. E. Os gêneros do discurso na sala de aula. In: ENCONTRO DO NÚCLEO DE ESTUDOS EM LINGUÍSTICA APLICADA, 1., 2010, Florianópolis. Palestra.

DEHAENE, S. Les neurones de la lecture. Paris: Odile Jacob, 2007.

DOLZ, J.; SCHNEUWLY, B. Gêneros orais e escritos na escola. Tradução e organização de Roxane Rojo e Glaís Sales Cordeiro. Campinas: Mercado de Letras, 2004.

ERICKSON, F. Metodos cualitativos de investigacion sobre la ensinanza. In: WITTROCK, M. C. (Org.). La investigación de la enseñanza, II: metodos cualitativos y de observación. Barcelona: Paidos, 1989. p.195-301. 
FERREIRO, E.; TeBerosky, A. Psicogênese da língua escrita. Porto Alegre: ARTMED, 2007.

GERALDI, J. W. Formação de professores. In: SEMINÁRIO DO PROFOR, UFSC, 2008, Florianópolis. Palestra. Portos de passagem. 4.ed. São Paulo: Martins Fontes, 1991.

HALTÉ, J. F. O espaço didático e a transposição. Fórum Linguístico, Florianópolis, v.2, n.5, p.117-139, jul./dez. 2008.

HAMILTON, M. Expanding the new literacy studies: using photographs to explore literacy as social practice. In: BARTON, D.; HAMILTON, M.; IVANIC, R. (Org.). Situated literacies. London: Routledge, 2000. p.16-34.

HEATH, S. B. What no bedtime story means: narrative skills at home and school. In: DURANTI, A. (Org.). Linguistic anthropology. a reader. Oxford: Blackwel, 2001. p.318-342.

INSTITUTO PAULO MONTENEGRO. Indicador de alfabetismo funcional. Brasil, 2009. Principais resultados. Disponível em: <http://www.ipm.org.br/download/ inaf_brasil2009_relatorio_divulgacao_final.pdf >. Acesso em: 08 fev. 2010.

IRIGOITE, J. C. S. Vivências escolares em aulas de Português que não acontecem: a (não) formação do aluno leitor e produtor de texto. 2011. 232f. Dissertação (Mestrado em Linguística) - Universidade Federal de Santa Catarina, Florianópolis, 2011.

KLEIMAN, A. (Org.). Os significados do letramento: uma nova perspectiva sobre a prática social da escrita. Campinas: Mercado de Letras, 1995.

MAINGUENEAU, D. Cenas da enunciação. São Paulo: Parábola, 2008.

2001.

. Elementos de linguística para o texto literário. São Paulo: Martins Fontes,

MATÊNCIO, M. L. M. Estudo da língua falada e aula de língua materna: uma abordagem processual da interação professor/alunos. Campinas: Mercado de Letras, 2001.

MOITA LOPES, L. P. (Org.). Por uma linguística aplicada indisciplinar. São Paulo: Parábola, 2006.

PIAGET, J. A epistemologia genética. São Paulo: Martins Fontes, 2007.

PETIT JEAN, A. Importância e limites da noção de transposição didática para o ensino do francês. Fórum Linguístico, Florianópolis, n.5, v.2, p.83-116, jul./dez. 2008.

ROJO, R. Letramentos múltiplos, escola e inclusão social. São Paulo: Parábola Editorial, 2009. 
SARDÁ, D. N. A leitura em um viés psicolinguístico: um olhar cognitivista sobre a performance de alunos de sexto ano do ensino fundamental no ato de ler. 2008. 150f. Trabalho de Conclusão (Graduação em Letras) - Centro de Comunicação e Expressão, Universidade Federal de Santa Catarina, Florianópolis, 2008.

STREET, B. Literacy. an advanced resource book. London: Routledge, 2007.

. Abordagens alternativas ao letramento e desenvolvimento. Teleconferência Brasil sobre o letramento, out. 2003a. Disponível em: <http:telecongresso.sesi. org.br Acesso em: 16 jan. 2012.

. What's "new" in new literacy studies? Critical approaches to literacy in theory and practice. Current Issues in Comparative Education, Columbia, n.5, v.2, maio 2003b.

. Practices and literacy myths. In: SALJO, R. (Ed.). The written world: studies in literate thought and action. Berlim: Springer-Verlag Press, 1988. p.59-72. 1984. . Literacy in theory and practice. Cambridge: Cambridge University Press, VIGOTSKI, L. A construção do pensamento e da linguagem. São Paulo: Martins Fontes, 2001. A formação social da mente. São Paulo: Martins Fontes, 2000.

Recebido em julho de 2010.

Aprovado em dezembro de 2010. 